\title{
Case report. Zinner-syndroom: een zeldzame oorzaak van agenesie van de nier
}

\author{
Manon J. te Dorsthorst · M. Prins-van Uden · Ronald Niekel · Michael R. van Balken
}

Published online: 14 January 2020

(C) The Author(s) 2020

\begin{abstract}
Samenvatting De trias nieragenesie, ipsilaterale retentiecyste van de vesicula seminalis en obstructie van de ductus ejaculatorius is een zeldzaam syndroom, dat in 1914 voor het eerst werd beschreven door dr. Zinner. Het syndroom ontstaat doordat tijdens de embryogenese een aberrante ductus mesonephricus (buis van Wolff) ontstaat en geen ureterknop wordt gevormd. Dit leidt tot ipsilaterale nieragenesie en obstructie van de ductus ejaculatorius, welke uiteindelijk leidt tot dilatatie van de vesicula seminales. De diagnose wordt meestal bij toeval gesteld, hoewel patiënten zich ook kunnen presenteren met klachten, zoals dysurie, frequency, urgency, hematurie/ hematospermie, scrotalgie en pijn bij ejaculatie. De diagnose wordt gesteld op basis van diverse beeldvormende technieken, waarbij de MRI-scan vaak het sluitende bewijs geeft. Dit case report het diagnose- en behandeltraject bij drie patiënten. Daarnaast wordt een overzicht van de embryologie en huidige stand van zaken binnen de beeldvorming en behandeling van het Zinner-syndroom gegeven.
\end{abstract}

Trefwoorden Zinner-syndroom · nieragenesie $\cdot$ cyste vesicula seminalis

\section{Case report. Zinner syndrome: rare cause of agenesis of the kidney}

Abstract The trias of renal agenesis, unilateral cyst of the vesicula and obstruction of the ductus ejaculatorius is a rare syndrome which was first described

drs. M. J. te Dorsthorst $(\varangle) \cdot$ dr. M. R. van Balken afdeling Urologie, Rijnstate Arnhem, Arnhem, Nederland mj.tedorsthorst@gmail.com

drs. M. Prins-van Uden · drs. R. Niekel

afdeling Radiologie, Rijnstate Arnhem, Arnhem, Nederland in 1914 by dr. Zinner. The syndrome is caused by an aberrant development of the mesonephric tubes (Wolff) and the absence of the ureteric bud during embryology. This leads to ipsilateral renal agenesis, unilateral cyst of the vesicula and obstruction of the ductus ejaculatorius which will lead to dilatation of the vesicle. While most patients may remain asymptomatic and are discovered incidentally, others do have symptoms like dysuria, frequency, urgency, hematospermia, scrotal pain and pain during ejaculating. Diagnosis could be set by a diversity of imaging, however by using MRI the syndrome will be recognized. In this case report we describe three patients who were diagnosed with Zinner syndrome. Besides we will describe an overview of the embryology and current state of imaging and treatment of the Zinner syndrome.

Keywords Zinner syndrome $\cdot$ renal agenesis $\cdot$ vesicle cyst

\section{Introductie}

Het Zinner-syndroom werd voor het eerst beschreven in 1914 en bestaat uit de trias van nieragenesie in combinatie met een retentiecyste van de vesicula seminalis en een ipsilaterale obstructie van de ductus ejaculatorius [1]. Het syndroom ontstaat door een aberrante vorming van de ductus mesonephricus (buizen van Wolff) en de afwezigheid van de ureterknop ten tijde van de embryogenese. Dit leidt tot ipsilaterale nieragenesie en obstructie van de ductus ejaculatorius, welke uiteindelijk leidt tot dilatatie van de vesicula seminalis [2, 3]. Het syndroom komt wereldwijd voor bij $0,0046 \%$ van de mannen [4].

Patiënten presenteren zich vaak voor het $40 \mathrm{e}$ levensjaar met diverse klachten, zoals dysurie, frequency, urgency, hematurie, hematospermie, scrotal- 
Figuur 1 Cystoscopie (a), MRI (b) en echo prostaat (c en d) van de patiënt uit casus 1 , waarop de retentiecyste van de vesicula seminalis is aangeduid met een asterisk en de blaas met een geel vlakje
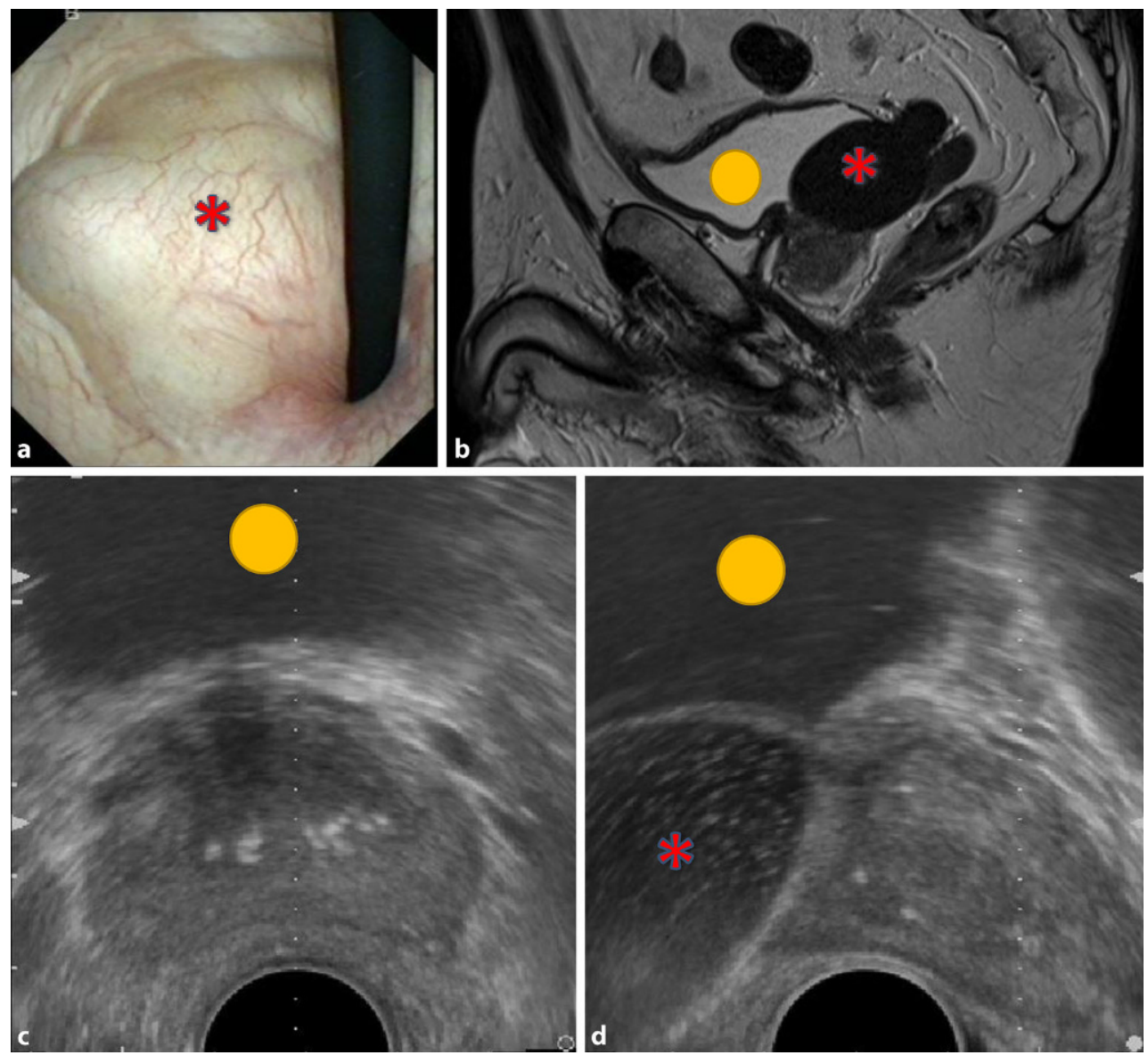

gie en pijn bij ejaculatie. Meestal wordt de diagnose echter bij toeval gesteld [5-7].

Binnen Rijnstate Arnhem hebben we in betrekkelijk korte tijd (< 10 jaar) drie patiënten met dit zeldzame syndroom gediagnosticeerd. In dit case report wordt een samenvatting van de reeds bekende literatuur gegeven met de focus op de diagnostiek en eventuele behandeling van dit syndroom.

\section{Casus 1}

Een 61-jarige patiënt met een blanco urologische voorgeschiedenis en zonder mictieklachten werd door de internist doorverwezen naar de uroloog in verband met een echografisch zichtbare blaaswandverdikking, agenesie van de rechternier op de CT-abdomen en verdenking op urotheelcelcarcinoom ter plaatse van rechterostium, met doorgroei in de ureter. De eGFR was $89 \mathrm{ml} / \mathrm{min} / 1,73 \mathrm{~m}^{2}$ meteen kreatinine van $81 \mu \mathrm{mol} / \mathrm{L}$. Bij cystoscopie werden geen afwijkingen aan het blaasslijmvlies gezien. Het rechterostium kon gedurende de cystoscopie niet worden geïdentificeerd en bij terugkijken bleek sprake te zijn van forse protrusie. Op de echo was het aspect van de prostaat normaal; de inhoud was $34 \mathrm{cc}$. Wel was rechts een forse vesicula zichtbaar (fig. 1). Er werd een MRIscan verricht voor nadere diagnostiek, omdat op de CT-scan een duidelijke wandverdikking te zien was en verdenking op maligniteit bleef bestaan. Als verklaring voor de bevindingen werd, naar aanleiding van de MRI-scan, de diagnose syndroom van Zinner gesteld. Omdat de patiënt geen klachten had en maligniteit niet werd aangetoond, bleef behandeling achterwege.

\section{Casus 2}

Een 56-jarige patiënt werd door de huisarts doorverwezen vanwege toenemende buikklachten aan de linkerzijde. In het verslag van de echo die op indicatie van de huisarts was gemaakt, stond 'waarschijnlijk congenitale afwezigheid van de linkernier in combinatie met ureterocele links'. De patiënt had, behoudens passagère erectiele disfunctie, een blanco urologische voorgeschiedenis. De eGFR was $83 \mathrm{ml} / \mathrm{min} / 1,73 \mathrm{~m}^{2}$ en een kreatinine van $89 \mu \mathrm{mol} / \mathrm{L}$. Bij cystoscopie werden er geen afwijkingen aangetroffen, maar wel verdenking op een ureterocele links; rechts was een ostium met efflux zichtbaar. In verband met de aanhoudende pijnklachten werd een MRI-scan vervaardigd, op grond waarvan de diagnose syndroom van Zinner werd gesteld (fig. 2). Na counseling over mogelijke chirurgische ingrepen werd op verzoek van de patiënt gekozen voor een expectatief beleid. 
Figuur 2 Cystoscopie (a), MRI (b) en echo prostaat (c) van de patiënt uit casus 2 , waarop de retentiecyste van de vesicula seminalis is aangeduid met een asterisk en de blaas met een geel vlakje
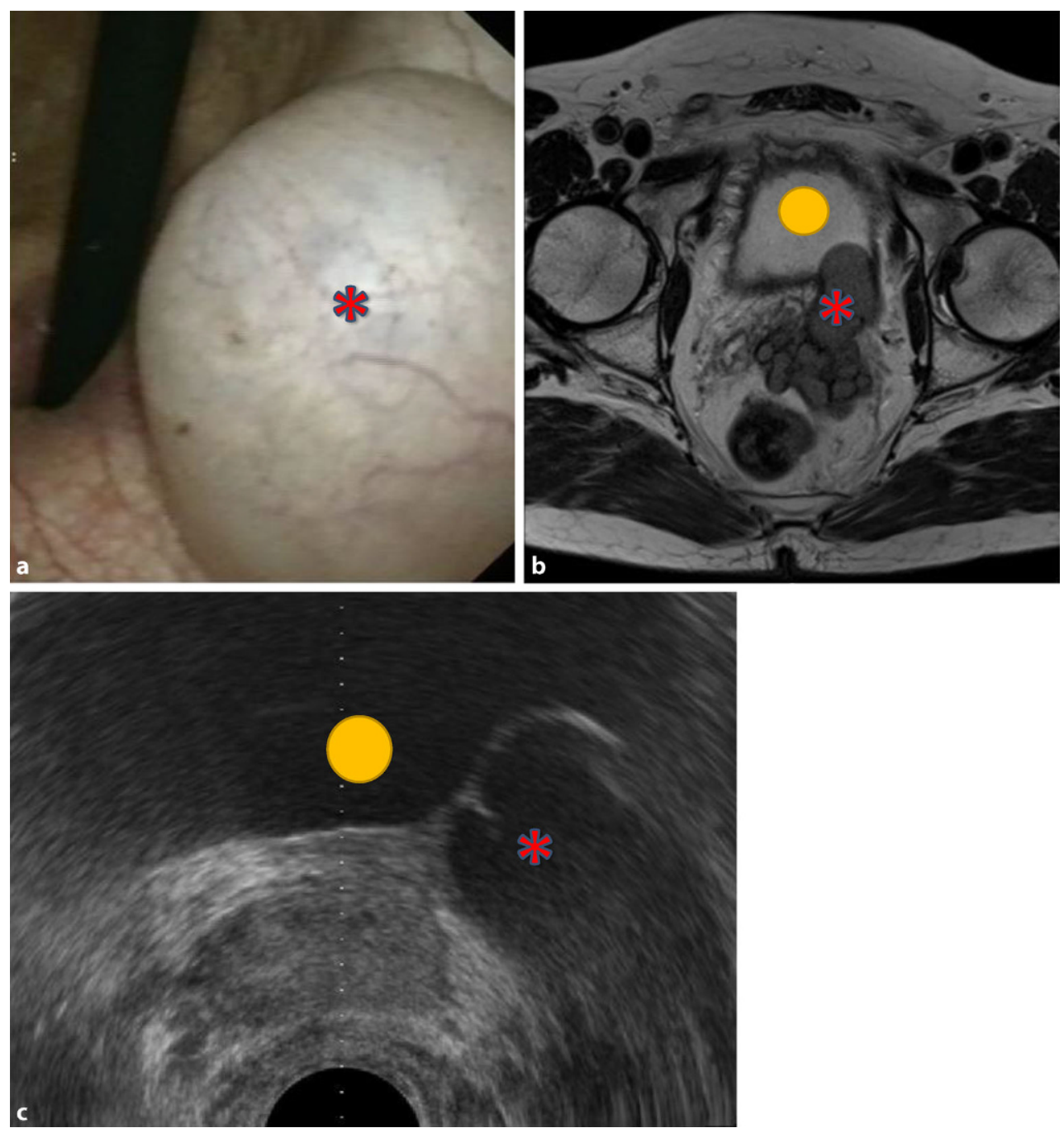

\section{Casus 3}

Een 67-jarige man werd verwezen naar de uroloog vanwege eenmalige urineretentie en plasklachten. Bij onderzoek (echo prostaat, cystoscopie en beeldvorming middels MRI) werd een prostaat van $25 \mathrm{cc}$ gezien met een $10 \mathrm{~cm}$ grote cyste van de vesicula seminalis links en agenesie van de linkernier. In eerste instantie werd conservatief beleid ingezet. De patiënt startte met een alfablokker. Daarna ontwikkelde hij geen retentie meer en mictieklachten in de vorm van verminderde straal bleven afwezig. Na twee jaar bleek de cyste gegroeid naar $15 \mathrm{~cm}$ en namen de mictieklachten toe. De cyste werd daarop door middel van open chirurgie verwijderd. Bij PA-onderzoek werd een cyste gezien met acute ulcererende en chronisch-fibroserende ontstekingsreactie met tekenen van doorgemaakte bloeding zonder maligne kenmerken.

\section{Discussie}

Het syndroom van Zinner is een trias van nieragenesie in combinatie met ipsilaterale retentiecyste van de vesicula en een obstructie van de ductus ejaculatorius [1]. Het syndroom wordt beschouwd als de mannelijke tegenhanger van het Mayer-Rokitansky-KustnerHauser-syndroom bij vrouwen (met congenitale aplasie dan wel hypoplasie van de vagina en de uterus) [8]. Toen de beeldvormende technieken minder geavanceerd waren, kon het syndroom van Zinner alleen postmortem worden vastgesteld of door middel van een rectaal toucher in combinatie met seminale vesiculografie (retrograde injectie in het ipsilaterale vas deferens) $[1,9,10]$.

De afwijkingen die leiden tot het syndroom van Zinner treden op in de vierde week van de embryologische ontwikkeling. De normale embryonale ontwikkeling van de nier verloopt van pronephros via mesonephros naar metanephros. Tijdens de vierde week ontwikkelt zich normaliter - vanuit het caudale deel van het mesonephros en een afsplitsing bij de buizen van Wolff - de ureterknop. De ureterknop ontwikkelt verder en komt samen met het metanefrogeen blasteem. Gedurende de daaropvolgende weken ontwikkelt zich uit beide structuren samen de nier. De ureter en het verzamelsysteem ontwikkelen zich vanuit 
de ureterknop, de nefronen differentiëren zich vanuit het metanefrogeen blasteem. Bij het syndroom van Zinner ontbreekt de ureterknop, wat leidt tot agenesie van de nier.

Bij de man ontstaan daarnaast uit de buizen van Wolff (ducti mesonephrici) het vas deferens, de epididymis, de vesicula, de efferente ductus en de paradidymis (overblijfsel van degeneratie van de mesonefrische tubulus aan de caudale zijde bij de ontwikkelende testis). Dit alles gebeurt onder invloed van testosteron en het Anti-Müllerian-hormone [11, 12]. Door het aberrant ontstaan van de buizen van Wolff ontwikkelt zich echter ook ook een retentiecyste van de vesicula seminalis en een ipsilaterale obstructie van de ductus ejaculatorius.

Tot op heden is er geen duidelijke genetische afwijking gevonden die correspondeert met het Zinnersyndroom. Wel zijn er diverse andere genetische oorzaken van nieragenesie bekend geworden (PAX2, EYA1, SIX1 mutaties) [12], maar deze mutaties zijn tot op heden niet gekoppeld aan het syndroom van Zinner.

De meeste patiënten met het syndroom van Zinner presenteren zich voor het 40e levensjaar met uiteenlopende klachten, waaronder problemen met fertiliteit. Zoals bovenstaande casus laten zien, kan de diagnose echter ook een toevalsbevinding zijn. In de literatuur is bij symptomatische patiënten transurethrale aspiratie van de vesicula beschreven, met of zonder achterlaten van alcohol en minocycline [13], maar ook andere laparoscopische of robotgeassisteerde chirurgische ingrepen $[6,14]$.

In de hier beschreven casus is bij twee van de drie patiënten een expectatief beleid gevoerd. Bij de laatste patiënt is een laparotomie uitgevoerd en excisie van het grootste gedeelte van een verdikte cystewand verricht, waarna de mictie verbeterde. Uit het pathologieverslag bleek dat bij deze patiënt sprake was van een cyste met acute ulcererende en een chronisch-fibroserende ontstekingsreactie met tekenen van doorgemaakte bloeding. Daarna werd een expectatief beleid gevoerd.

\section{Conclusie}

De trias nieragenesie, ipsilaterale retentiecyste van de vesicula seminalis en obstructie van de ductus ejaculatorius komt zelden voor. Echter, bij unilaterale afwijkingen aan de prostaat en het trigonum zou men kunnen denken aan afwijkingen van ook de hogere urinewegen. Symptomen die bij het syndroom van Zinner kunnen voorkomen, zijn overactieve blaas, obstructieve mictieklachten en scrotale pijnklachten. Ook kunnen zich problemen voordoen met de fertiliteit. De diagnose wordt veelal gesteld op grond van een MRI-scan met aanvullend een echo prostaat. Met name deze laatste beeldvorming zou - ondanks de vaak atypische presentatie - voldoende moeten zijn voor het stellen van de diagnose. Of behandeling wordt ingezet, is afhankelijk van de symptomen, maar het syndroom van Zinner is niet altijd symptomatisch.

Open Access This article is distributed under the terms of the Creative Commons Attribution 4.0 International License (http://creativecommons.org/licenses/by/4.0/), which permits unrestricted use, distribution, and reproduction in any medium, provided you give appropriate credit to the original author(s) and the source, provide a link to the Creative Commons license, and indicate if changes were made.

\section{Literatuur}

1. Zinner A. Ein fall von intravesikaler Samenblasenzyste. Wien Med Wochenschr. 1914;64(605):e9.

2. Fiaschetti V, Greco L, Giuricin V, De Vivo D, Di Caprera E, Di Trapano R, et al. Zinner syndrome diagnosed by magnetic resonance imaging and computed tomography: role of imaging to identify and evaluate the uncommon variation in development of the male genital tract. Radiol Case Rep. 2017;12(1):54-8.

3. Kanavaki A, Vidal I, Merlini L, Hanquinet S. Congenital seminal vesicle cyst and Ipsilateral renal Agenesis (Zinner syndrome): a rare association and its evolution from early childhood to adolescence. European J Pediatr Surg Rep. 2015;03(02):98-102.

4. Farooqui A, AlDhahir L, MahfoozA. Massive seminal vesicle cyst with ipsilateral renal agenesis - Zinner syndrome in a Saudi patient. UrolAnn. 2018;10(3):333-5.

5. Sundar R, Sundar G. Zinner syndrome: an uncommon cause of painful ejaculation. BMJ Case Rep. 2015; Mar $6 ; 2015$.

6. Jarzemski P, Listopadzki S, Kowalski M. Laparoscopic removal of a congenital seminalvesicle cyst inZinner's syndrome. JSLS. 2014;18(2):367-71.

7. Haddock P, Wagner JR. Seminal vesicle cyst with ipsilateral renal agenesis and ectopic ureter (Zinner syndrome). Urology. 2015;85(5):e41-e2.

8. Gianna P, Giuseppe PG. Mayer-Rokitansky-Küster-Hauser syndrome and the Zinner syndrome, female and male malformation of reproductive system: are two separate entities. JChin Clin Med. 2007;2:11.

9. Heetderks DR, Delambre LC. Cyst of the seminal vesicle. JUrol. 1965;93(6):725-8.

10. Hart JB. A case of cyst or hydrops of the seminal vesicle. JUrol. 1961;86(1):137-41.

11. Hannema SE, Hughes IA. Regulation of Wolffian duct development. Horm Res. 2007;67(3):142-51.

12. Schoenwolf GC, et al. Larsen's human embryology. 4e druk. Londen: Churchill LivingstoneElsevier;2009. pag.479-542.

13. Williams RD, Sandlow JI. In: Walsh PCRA, Vaughan ED, Wein AJ, redactie. Surgery of the seminal vesicles. Campbell's urology 7. Philadelphia: Saunders; 1998. pag.3299-307.

14. Razdan S, Kryvenko ON, Razdan S. Robotic-assistedlaparoscopic vesiculectomy in a patient with atypical Zinner syndromepresenting withlarge cystinvolvingbilateral seminal vesicles and vasa deferentia. Urol Case Rep. 2018;18:79-81.

drs. Manon J. te Dorsthorst, anios urologie

drs. M. Prins-van Uden, aios radiologie

drs. Ronald Niekel, radioloog

dr. Michael R. van Balken, uroloog 